\title{
DECISION-MAKING UNDER UNCERTAINTY: A HEURISTICS OVERVIEW AND THE ANALYTIC NETWORK PROCESS
}

\section{M.A. MILKOVA ${ }^{\mathrm{a}}$, A.V. ANDREICHICOV ${ }^{\mathrm{b}}$, O.N. ANDREICHICOVA ${ }^{\mathrm{a}}$}

\author{
${ }^{a}$ Central Economics and Mathematics Institute, Russian Academy of Science, 47, Nakhimovsky Prospect, \\ Moscow, Russian Federation, 117418 \\ ${ }^{b}$ Russian University of Transport, Moscow State University of Railway Engineering (MIIT), 9 Bld. 9, \\ Obraztsova Str., Moscowe, Russian Federation, 127055
}

\begin{abstract}
The paper provides an overview of known heuristic techniques and different views on decisionmaking based on heuristics. We discuss heuristics of the "heuristics and biases" program introduced by Daniel Kahneman and Amos Tversky, and heuristics of the "fast and frugal heuristics" program developed by Gerd Gigerenzer and colleagues. We propose the idea that heuristics, being a natural instrument of human assessment, may be applied not only for the simplification of the decision process, but also in deliberate strategies without sufficiently reducing the complexity of a problem. In light of this, we give an overview of the Analytic Network Process methodology as a cognitive process. The Analytic Network Process is a descriptive psychophysical process developed by the mathematician, a distinguished University Professor at the University of Pittsburgh, Thomas L. Saaty in the 1980s, and it is used for large-scale, multi-criteria decision analysis. It represents the decision problem as a network structure with dependences and feedbacks between included criteria and alternatives. Whether applying heuristics may help to answer questions like "which of the two elements influence more", pairwise comparisons of considered elements give more accurate answers on "how strong is this influence". The aim of this article is to draw the attention of psychologists to the interdisciplinary research of the Analytic Network Process that has only been previously studied as a mathematical algorithm, and not as a cognitive process.
\end{abstract}

Keywords: decision-making under uncertainty, heuristics and bias, fast and frugal heuristics, analytic network process.

\section{Introduction}

In psychology decision-making is regarded as cognitive processes by which a preferred strategy is chosen from among several alternatives based on different criteria.

The reported study was funded by the RFBR according to the research project № $19-010-00293$ "Development of methodology, economic and mathematical models, methods and decision support systems for search studies to identify opportunities for import substitution of high-tech products based on the world patent and financial information resources". 
According to Wang and Wang (2006), "decision-making is one of the fundamental cognitive processes of human beings widely used in determining rational, heuristic, and intuitive selections in complex scientific, engineering, economical, and management situations, as well as in almost each procedure of daily life".

Many important problems involve decision-making under uncertainty - that is, choosing actions based on observations that are often imperfect, with unknown outcomes. While rational thinking is common in making decisions, analytical approaches lose their relevance when the probabilities of uncertain events are not adequately computed in formal models. In that case heuristics is often the only practical method for decision-making under uncertainty.

The term "heuristics" implies an efficient cognitive process, conscious or unconscious, that ignores part of the information (Gigerenzer \& Gaissmaier, 2011). The classical view on heuristics states that heuristic decisions imply greater errors than "rational" decisions do as defined by logic or statistical models. On the other hand, recent experiments show that in some cases a right heuristic can be more effective than an advanced approach (Mousavi \& Gigerenzer, 2014).

But could we apply heuristics without sufficiently reducing the complexity of a problem? Could heuristics be part of the analytical approach? Could mathematical theory describe the cognitive process?

In this article we discuss heuristic and analytical approaches in decision-making under uncertainty. We provide an overview of known heuristic techniques as well as Analytical Network Process Methodology - a multicriteria decision-making method developed by T. L. Saaty. We assume that it is heuristics that is critical for decision-making with the Analytical Network Process.

\section{A Heuristics Overview}

Frank Knight (1921) was the first who argued that generating economic profit is related to making entrepreneurial decisions under uncertainty. However, situations of uncertainty occur in a wide range of decisions in everyday life. Mousavi and Gigerenzer emphasized that "each of these uncertain situations can be too unique to lend any useful data to statistical analysis and hence preclude not only explicit attainment of even near-perfect knowledge but also measurable probability" (Mousavi \& Gigerenzer, 2014).

H. A. Simon proposed an alternative concept of the mathematical modeling of decision-making. In Simon (1957) he introduced a theory of "bounded rationality" - the idea that when individuals make decisions, their rationality is limited by the tractability of the decision problem, the cognitive limitations of their minds, and the time available to make the decision. Simon argued that people tend to use heuristics while making decisions rather than rational algorithms. Thus, people act as "satisficers", seeking a satisfactory decision rather than an optimal one.

Simon's concept of satisficing (Simon, 1956) postulates that an organism would choose the first alternative that satisfies its aspiration level. It would not take the time to range all available alternatives by estimating probabilities and utilities for each possible alternative and calculating expected utilities. 
Exploring the territory of bounded rationality that Simon had defined, Amos Tversky and Daniel Kahneman developed their own perspective on heuristics in human decision-making. Tversky, Kahneman (1974) described three judgmental heuristics - representativeness, availability, and anchoring and adjustment - that underlie many intuitive judgments under uncertainty.

The representativeness heuristic is usually used when people judge the likelihood that an object belongs to a general category or a class based on the similarity of the object to members of that category.

Consider the situation:

Bob enjoys visiting opera and art museums, and playing chess with his friends. Which of the following situation is more likely?

A. Bob plays violin in a symphony orchestra

B. Bob is a manager

A large percent of people will choose Situation A in the problem presented, because Bob's description corresponds to the stereotype we may associate with classical musicians rather than with managers. In fact, the probability of Alternative B is greater, because managers make up a much larger proportion of the population.

The availability heuristics is used when people evaluate the frequency or the probability of an event by the ease with which a given event comes to mind. Thus, in assessing the likelihood of an event, a person relies on a limited number of examples from the past. If an event that rarely occurs easily comes to mind, people tend to overestimate its probability. For example, investors may judge the quality of an investment based on facts from mass media and ignore other important information (Tversky \& Kahneman, 1974).

The anchoring and adjustment heuristics is usually employed in numerical prediction when people make judgments by starting from an anchor - an initial value that works as a starting point and affects the final decision. Different starting points yield different estimates that are biased toward the initial values. For example, participants received comprehensive information regarding a property, including either a high or low list price, before viewing the property. Finally, participants were asked to estimate the actual value of the property. When the list price was high, final estimates also tended to be elevated.

In their experiments Tversky and Kahneman showed that people acting under uncertainty "rely on a limited number of heuristic principles that reduce the complex tasks of assessing probabilities and predicting values to simpler judgmental operations" (Tversky \& Kahneman, 1974; Kahneman, 2003). Nevertheless, Kahneman and Tversky (1996) argue that cognitive biases have efficient practical implications for areas including clinical judgment, entrepreneurship, finance, and management.

In a subsequent work Kahneman and Frederick (2002) proposed a process called "attribute substitution", which means that a judgment is said to be mediated by a heuristic when an individual assesses a specified target attribute of an object of judgment by substituting a related heuristic attribute that comes more readily to mind. 
Thus, according to Kahneman and colleagues, usage of heuristics implies that it saves effort, but at the cost of accuracy. As information search and computation is expensive in terms of time and effort, humans rely on heuristics that trade off some loss in accuracy for faster and more frugal decision (Gigerenzer \& Gaissmaier, 2011).

In contrast, Gerd Gigerenzer and colleagues pursued an approach that heuristics do not depend on a compromise between accuracy and effort - their simplicity is the reason they work well, by properly matching the heuristic approach with the environment (Mousavi \& Gigerenzer, 2014). Heuristics are "fast and frugal" and deal with simple, task-specific decision strategies that can be used to make accurate and unbiased judgments.

Gigerenzer conceptualized rational decisions in terms of the adaptive toolbox (the repertoire of heuristics an individual or institution has) and the ability to choose good heuristics for the task at hand. He used the term "ecological rationality" that "refers to functional matches between cognition and environment, and thus generates insight for engineering environments that are most conducive to achieving certain tasks" (Gigerenzer, Hertwig, \& Pachur, 2011; Todd, Gigerenzer, $\&$ the ABC Research Group, 2012).

Thus, fast and frugal heuristics are ecologically rational, which means that fast and frugal heuristics present a strategy that effectively corresponds to the structure of information in the environment According to Gigerenzer and colleagues (Mousavi \& Gigerenzer, 2014), the effectiveness of this ecological match does not simplify the complex structure of the environment. Heuristic strategies in fact mimic the complexity of the environment. For example, in order to reduce the estimation error and effort people can ignore available information for estimating correlations from a sample. But "in an uncertain world, less often proves to be more" (Ibid.).

This less-is-more effect Gigerenzer describes through the inverse-U-shaped relation between the level of accuracy and the amount of information, computation or time. The U-shaped relation implies that, at a certain point, more information does not improve the decision quality, but harms it (Todd et al., 2012). The reason why this less-is-more effect can produce positive outcomes is that heuristics are not randomly applied. They are adapted to suit the particular decision environment in which they are employed (Gigerenzer \& Gaissmaier, 2011).

Gigerenzer \& Gaissmaier (2011) review four classes of fast and frugal heuristics: 1) recognition-based heuristics that exploit recognition memory: 2) one-reason heuristics that rely on one good reason only (and ignore all other reasons); 3) trade-off heuristics that weigh all cues; 4) social heuristics that rely on social information.

Based on Schulkin (2012) and Gigerenzer, Gaissmaier (2011) we aggregate well-studied fast and frugal heuristics with evidence of use in the adaptive toolbox and examples of heuristics in each class (see Table 1).

Thus, the studies of fast and frugal heuristics have shown that less effort can lead to more accurate judgments. Nevertheless, a criticism of the less is more effect also occurs in the literature (see, for example, Pachur \& Biele, 2007; Pohl, 2006), possibly because the effect is supposed to be small (see Katsikopoulos et al., 2010). 


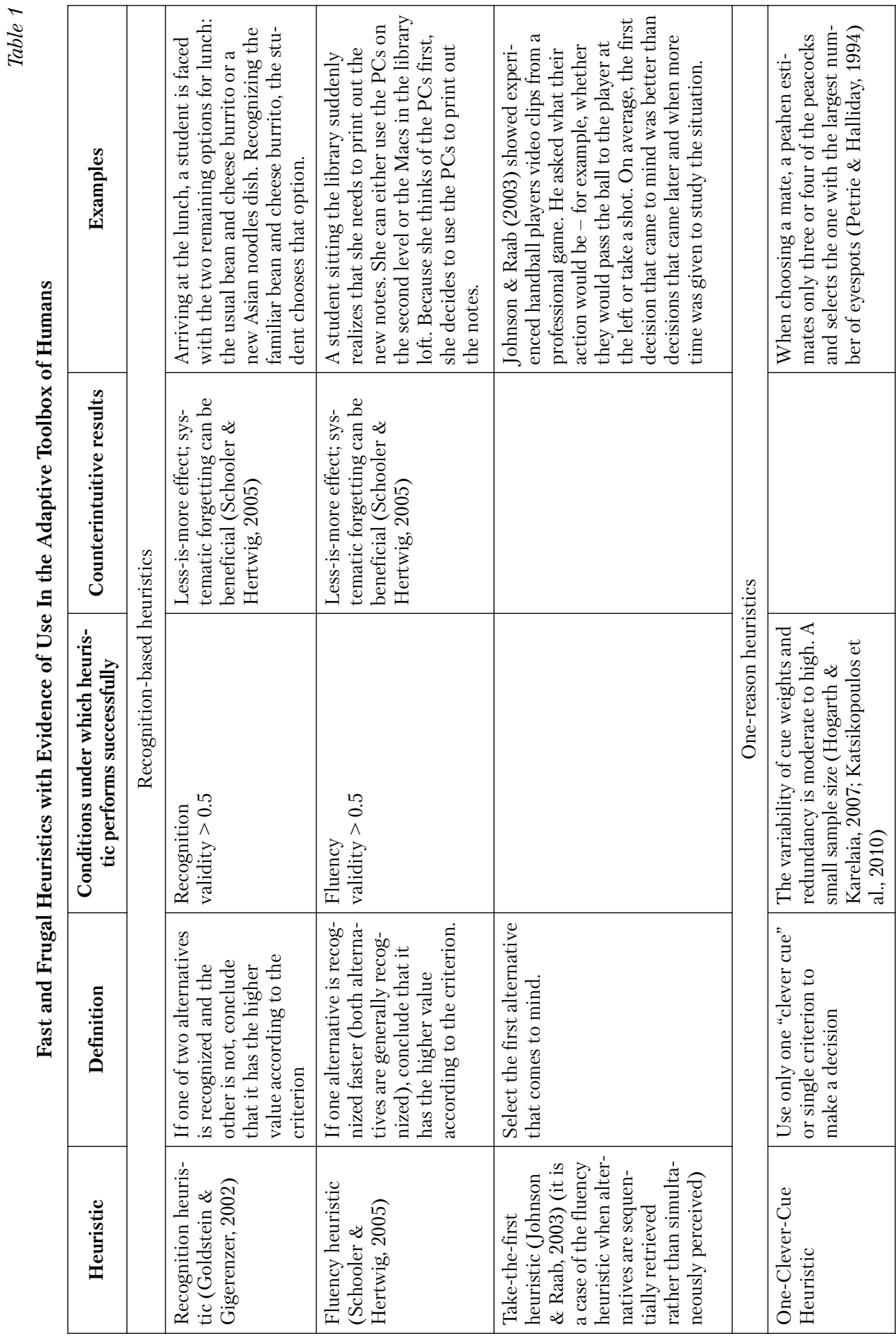




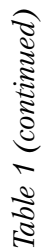

\begin{tabular}{|c|c|c|c|c|c|}
\hline 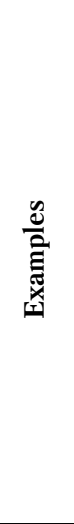 & 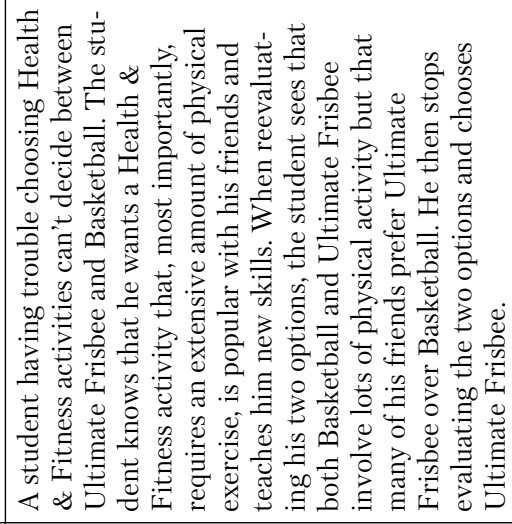 & 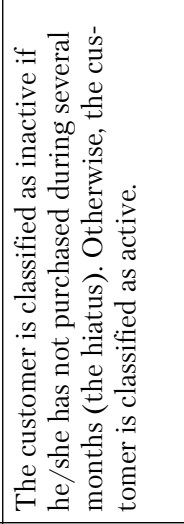 & \multirow[b]{3}{*}{ 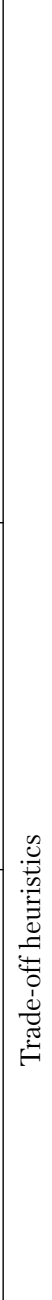 } & 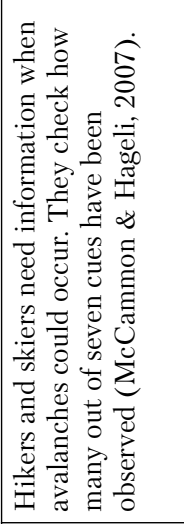 & 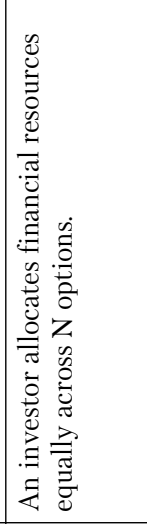 \\
\hline 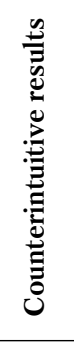 & 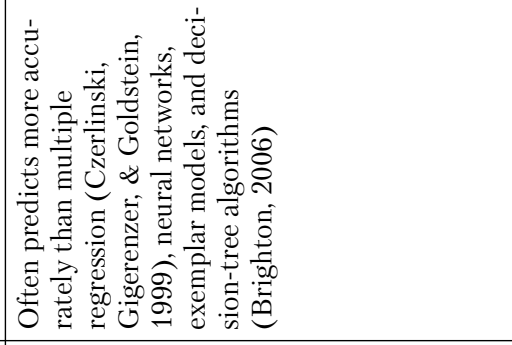 & 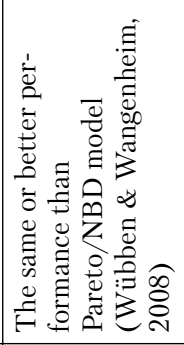 & & 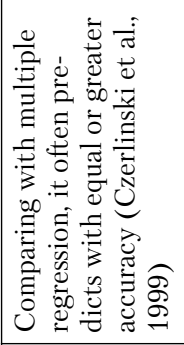 & 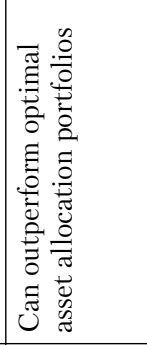 \\
\hline 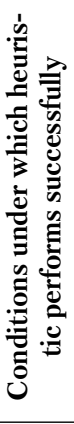 & 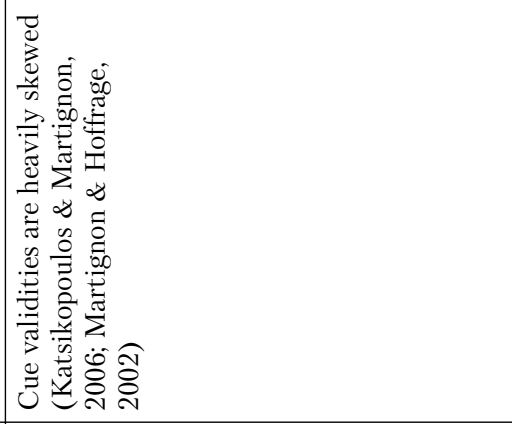 & & & 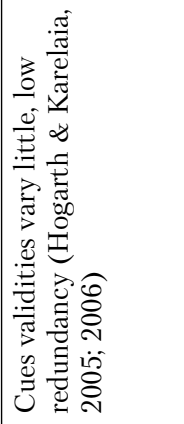 & 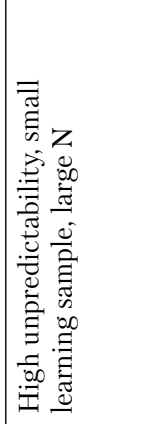 \\
\hline 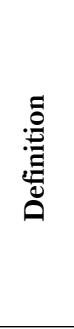 & 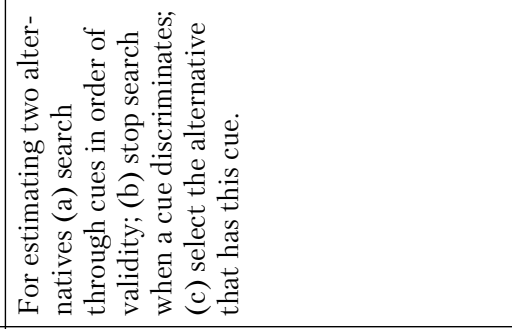 & 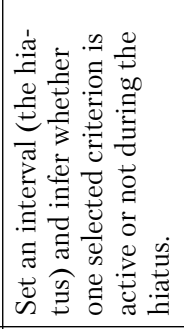 & & 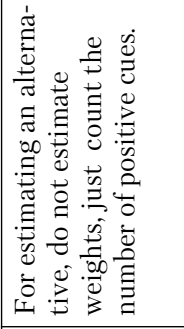 & 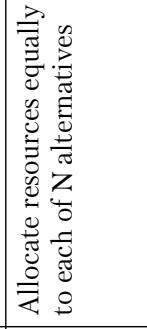 \\
\hline 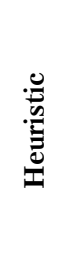 & 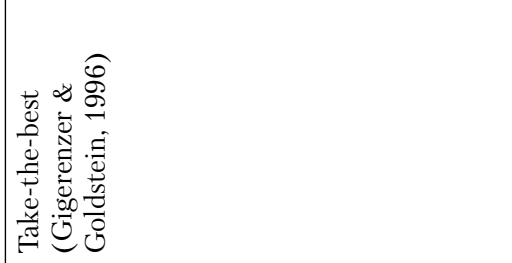 & 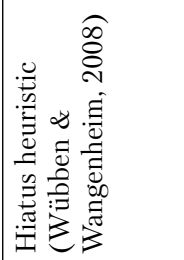 & & 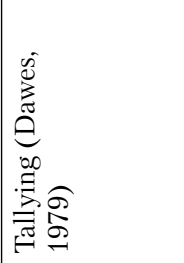 & 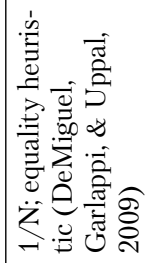 \\
\hline
\end{tabular}




\begin{tabular}{|c|c|c|c|c|c|}
\hline$\underset{\substack{\tilde{u} \\
\tilde{E}}}{\tilde{E}}$ & \multirow{5}{*}{ 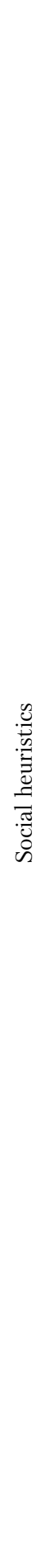 } & 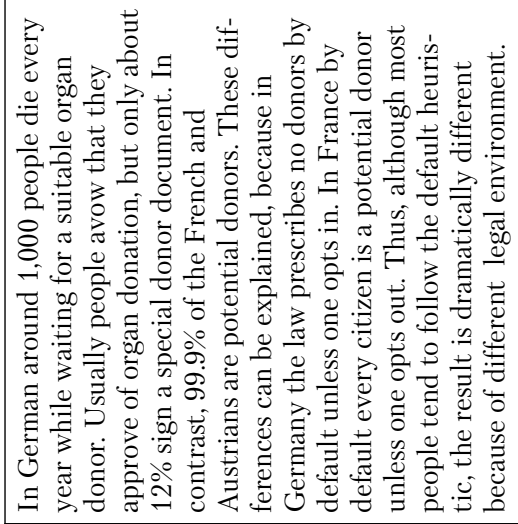 & & & \\
\hline 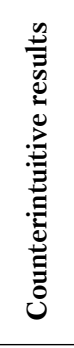 & & 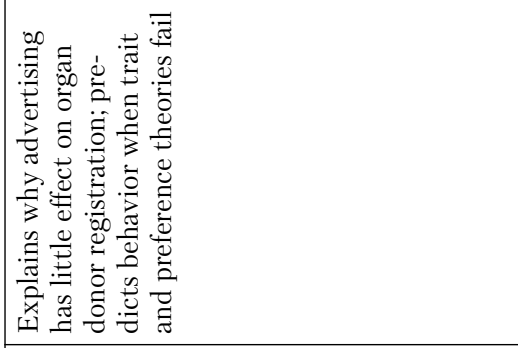 & 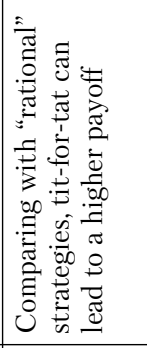 & 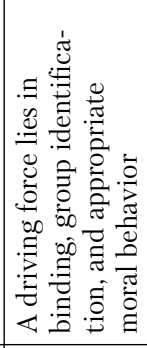 & 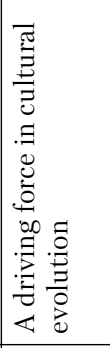 \\
\hline 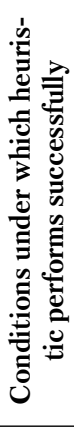 & & 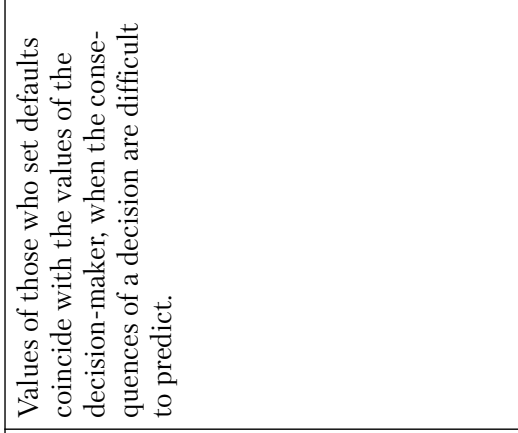 & 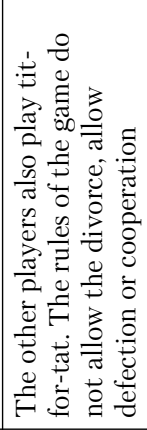 & 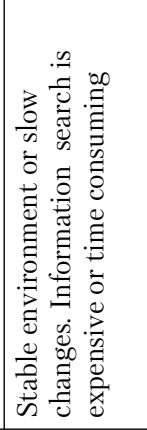 & 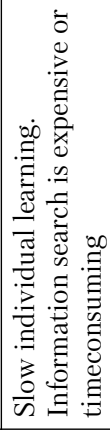 \\
\hline 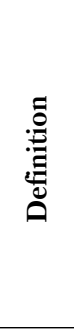 & & 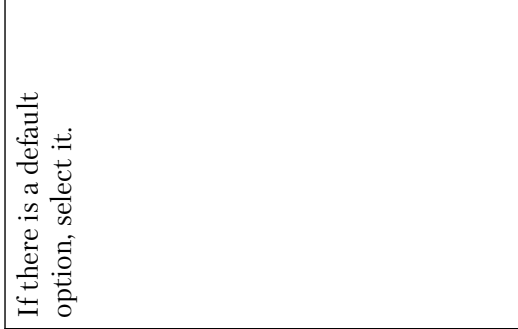 & 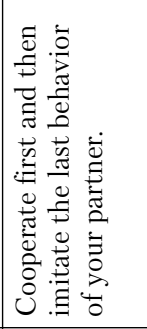 & 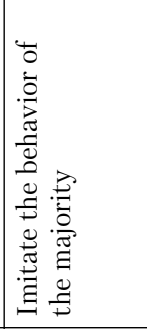 & 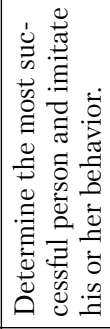 \\
\hline 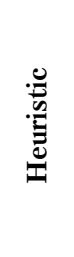 & & 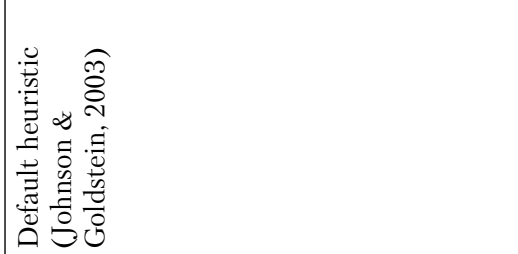 & 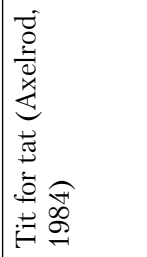 & 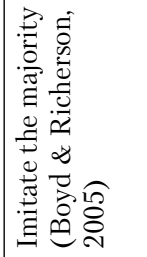 & 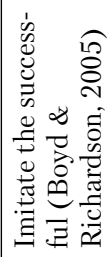 \\
\hline
\end{tabular}


Anyway, the results of all research put heuristics on par with the standard statistical models of "rational” cognition (Gigerenzer, 2008).

In Gilovich et al. (2002) authors clarify the differences and similarities between the heuristics of the "heuristics and biases" program and those of the "fast and frugal heuristics" program. Comparison of the programs is based on the "dual process" models of cognition.

Dual process theory provides an idea of how a phenomenon can occur in two different ways, or as a result of two different processes. There are various dual process models and each of them postulates one set of mental processes that are quick and effortless, and another of those that are more deliberate and taxing.

There are two types of dual process models. The first one uses the "cognitive miser" perspective on heuristic processing, implying that humans tend to solve problems in simpler and less effortful ways rather than in more sophisticated and more effortful ways, regardless of intelligence (Stanovich, 2009).

Another set of dual-process models do not conform to the cognitive miser perspective. These models, often referred to as "two systems" models, postulate the existence of two mental systems that operate in parallel (Kahneman, 2003). An associationist, parallel-processing system ("System 1") that renders quick, holistic judgments is always in operation - not just when motivation is low and judgments are made on the cheap. The assessments made by the associationist system are then supplemented (and sometimes overridden) by the output of a more deliberate, serial, and rule-based system ("System 2").

Gilovich and colleagues (2002) notice that the heuristics and biases program has most often been seen through a cognitive miser lens, and people are thought to employ various heuristics to save effort. But the idea of heuristics as "natural assessments" (Tversky \& Kahneman, 1983) is clearly much more consistent with the two-systems perspective.

The prototypical fast and frugal heuristics are "System 2" heuristics: strategies or rules that are deliberately chosen to ease the computational burden. Some of the "System 2" heuristics, however, rest on more basic "System 1" processes that are subject to the kinds of errors associated with the heuristics and biases approach. Thus, the accuracy of the ("System 2") decision rule rests on the validity of a "System 1" computation, which is sensitive to a wide variety of environmental manipulations that lead to robust and systematic biases (e.g., Kelley \& Jacoby, 1996; Reber, Winkielman, \& Schwarz, 1998). It seems that "System 1" heuristics, and the biases that arise from them, are difficult to avoid even in the context of deliberate choice (Frederick, 2002).

\section{The Analytic Network Process as a Cognitive Process}

In spite of different views concerning the nature of heuristics, the incontestable fact is that in a world of uncertainty heuristics is an indispensable tool. But how could we apply heuristics for making decisions in complex situations, where it is necessary to assess the problem not in terms of benefits, but also in terms of opportunities, costs and risks? Is there an opportunity to apply heuristics without sufficiently reducing the complexity of a problem? 
In light of these questions we discuss the Analytic Network Process (ANP) methodology for decision-making. The methodology is well-known among mathematicians and economists, and less known among psychologists, although it is heuristics that is on the basis of decision-making with ANP.

ANP was developed at 1980s by the mathematician Thomas L. Saaty and is used for large-scale, multi-criteria decision analysis (MCDA). ANP is a descriptive psychophysical process (Saaty, 2013). This means that ANP assumes that judgments about subjective feelings and sensations are not very different from and depend upon assessments of the physical world, where we receive understanding and experience of the reality. It is important that assessments must represent not only our knowledge about influences, but also the strengths with which these influences occur. The strength of influences is expressed by us, through assessments from which we derive priorities in relative forms that reflect numerical intensities (Saaty, 2008, b).

Continuing the idea that our decisions are governed more by heuristics than by logic, how we do it conforms to the natural human practice of making comparisons. Saaty suggested a scientific way of constructing a subjective scale that can be applied to a diverse range of issues being assessed (Saaty, 2008, a).

Based on Weber's law (that the change in a stimulus is noticed when it is increased by a constant ratio of the original stimulus), the idea of just noticeable differences (JND), and Fechner's law (that the subjective sensation is proportional to the logarithm of the stimulus intensity), Saaty came to the idea that positive integers are an integral part of our ability to compare (Saaty, 2009, a). Psychological experiments have shown that individuals cannot simultaneously compare more than seven objects (plus or minus two) (Miller, 1956). Thus, we can mentally represent the meaning of numbers 1 through 9 with actual acuity (Dehaene, 1997). In other words, people are able to distinguish between high, medium and low at one level and for each of them in a second level below that also distinguish between high, medium and low giving us nine different categories. We don't need to keep in mind more than $7 \pm 2$ elements because of the increase in "inconsistency" when we compare more than about 7 elements (Saaty, 2009, a).

Table 2 gives definitions and explanations for the Fundamental Scale of Absolute Numbers (Ibid.).

The Fundamental Scale may be used by making paired comparisons of two elements at a time using the smaller one as a unit and estimating the larger element as a multiple of that unit regarding their common criterion.

Note that the task of comparisons involves an inference in which one could rely on judgmental heuristics (such as availability or anchoring and adjustment). Because judgments in ANP may be skewed due to attribute substitution, the integrity of the measurement system is monitored using the Consistency Ratio (CR) - a measurement tool of how consistent the judgments have been in relation to large samples of purely random judgments (for details see Saaty, 2001).

Validity of using the Fundamental Scale in making comparisons has been proven in practice and validated by physical and decision problem experiments, where pairwise comparisons were tested using tangibles to improve confidence when using it with intangibles (see Saaty, 2008, a). 
The Fundamental Scale of Absolute Numbers

\begin{tabular}{|c|l|l|}
\hline $\begin{array}{c}\text { Intensity of } \\
\text { Importance }\end{array}$ & \multicolumn{1}{|c|}{ Definition } & \multicolumn{1}{c|}{ Explanation } \\
\hline 1 & Equal Importance & $\begin{array}{l}\text { Two activities are equally preferred in terms of pur- } \\
\text { pose }\end{array}$ \\
\hline 3 & Moderate importance & One of the activities is slightly preferable to the other \\
\hline 5 & Strong importance & $\begin{array}{l}\text { One of the activities is much more preferable to the } \\
\text { other }\end{array}$ \\
\hline 7 & $\begin{array}{l}\text { Very strong or demon- } \\
\text { strated importance }\end{array}$ & $\begin{array}{l}\text { An activity is considered much more preferable to the } \\
\text { other ; the dominance is confirmed by practice }\end{array}$ \\
\hline 9 & $\begin{array}{l}\text { Extreme importance } \\
\text { The evidence of the overwhelming preference of one } \\
\text { activity over another has undeniable confirmation }\end{array}$ \\
\hline Reciprocals & $\begin{array}{l}\text { If activity i is assigned value A compared with activity j, then activity } \mathrm{j} \text { has } \\
\text { value 1/A when compared with i. }\end{array}$ \\
\hline
\end{tabular}

In Saaty (Ibid.) an experiment was shown where five geometric areas were compared in pairs by eyeballing to reproduce their relative size (see Figure 1).

We present the results of Saaty's experiment (Ibid.) in Table 3. Every cell of the table contains the result of a pairwise comparison of an area indicated on the left with another indicated at the top. The value is the answer to the question: "How many times more, or how strongly more is that area bigger than the one at the top First, the verbal explanation is used to make a judgment and then its numerical value is entered. For example one enters 9 in the first row and second column (circle-triangle position) that means that circle is extremely larger than the triangle. In the second row and first column (triangle-circle position) it is automatically entered 1/9. One always enters an integer number in the considered position and its reciprocal value is entered automatically in the transpose position.

Table 3 contains the column of Priorities (or so called Eigen Vector, or the Priority Vector). The Priority Vector is calculated as follows: at first the matrix is raised to large powers, then the total value of the row is divided by the total sum of all the rows (for more details see Ibid).

Table 3 also represents the actual relative measurements in the last column. We see that the results of the visual area comparisons and actual relative sizes are very close.

In Saaty (Ibid.) three forms of general comparisons of the dominance of one object over another were demonstrated, with respect to a considered attribute or criterion: importance or significance, preference as in making decisions, and likelihood as in 
Five Figures Drawn with Appropriate Size of Area
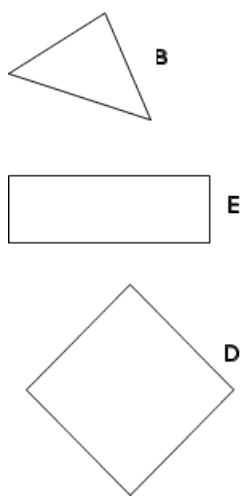
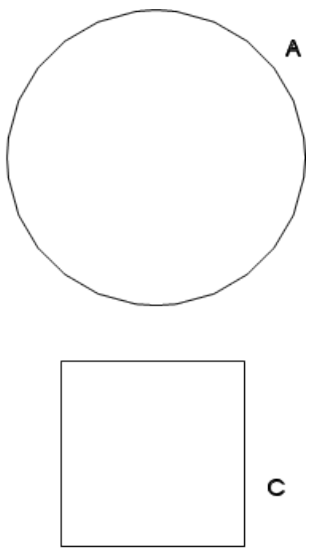

Table 3

The Results of the Geometric Shape Comparisons Experiment (Saaty, 2008a)

\begin{tabular}{l|c|c|c|c|c|c|c}
\multicolumn{1}{c|}{ Figure } & Circle & Triangle & Square & Diamond & Rectangle $\begin{array}{c}\text { Priorities } \\
\text { (Eigen } \\
\text { Vector) }\end{array}$ & $\begin{array}{c}\text { Actual } \\
\text { Relative } \\
\text { Size }\end{array}$ \\
\hline Circle & 1 & 9 & 2 & 3 & 5 & 0.462 & 0.471 \\
\hline Triangle & $1 / 9$ & 1 & $1 / 5$ & $1 / 3$ & $1 / 2$ & 0.049 & 0.050 \\
\hline Square & $1 / 2$ & 5 & 1 & $3 / 2$ & 3 & 0.245 & 0.234 \\
\hline Diamond & $1 / 3$ & 3 & $2 / 3$ & 1 & $3 / 2$ & 0.151 & 0.149 \\
\hline Rectangle & $1 / 5$ & 2 & $1 / 3$ & $2 / 3$ & 1 & 0.093 & 0.096
\end{tabular}

probabilities. If we have enough experience and adequate knowledge, we can compare any object with anything else that shares a common attribute or criterion. Thus, "comparisons go beyond ordinary measurement to include intangibles for which there are no scales of measurement" (Saaty, 2015).

In order to make decisions in our complex life we must have adequate structures that represent our knowledge of the flow of influences. ANP represents the decision problem as a network structure with dependences and feedbacks between included criteria and alternatives (Saaty, 2001, 2006). A simplification of ANP also exists - it is the Analytic Hierarchy Process (AHP), where a decision problem is represented through hierarchy (Saaty, 1990). In this article it is ANP that we focus on, as a generalization of AHP.

A network consists of clusters and nodes (or elements) in each cluster (see Figure 2). Each element of the cluster has its own links with the elements from another cluster (outer dependence) or the same cluster (inner dependence). In Saaty $(2008$, a) there is an example that illustrates outer and inner dependences: In a family of a father, a mother and a child the child was asked who influenced more his survival and success: 1) his/her father or mother, 2) itself or their father, 
3 ) itself or their mother. In this case the contribution of the child is little (outer dependences, no inner dependence). But if we asked the same question to the mother, (Who contributed to her survival and success more?): 1) herself or her husband, 2) herself or her child, 3) her husband or her child, herself would be higher (inner dependence).If we think about it carefully, in our life everything can be seen to influence everything including itself according to many criteria. Our world has a great number of dependences and interdependences. Using our existing ways of thinking and acting we cannot deal with this complexity. According to Saaty, a fundamentally new perspective on this problem is offered by the ANP, which is our logical way to deal with dependences (Saaty, 2008, b).

Networks in ANP decision-making are associated with the structure of the human brain. As the brain works through the functioning of its networks of neurons, where neurons are decision-makers deciding to fire or not to fire, interactions of the neurons are similar to those of the flow of influences in decision-making (Saaty, 2015). Thus, our perception of reality is better represented through a network that enables us to more accurately understand, control, and predict happenings in the world around us.

As an example, in Saaty $(2008, \mathrm{~b})$ the ANP model was developed to determine the relative market share of three United States competitors in a retail business: Walmart, Kmart, and Target. The task was to build network structures and consider the influences and dependences that affect the market share (Figure 3). No actual statistics are used in this example, but only expert's judgments about the relative influence. The decisions alternatives are competitors.

Then, so called "supermatrix" is constructed. Each Priority Vector, calculated from pairwise comparison matrixes, fills the corresponding column in a supermatrix to represent the impact of elements in a cluster on an element in another cluster or on elements of the cluster itself. The elements, grouped by the clusters they

The ANP Network Diagram (Saaty, 2008, b)

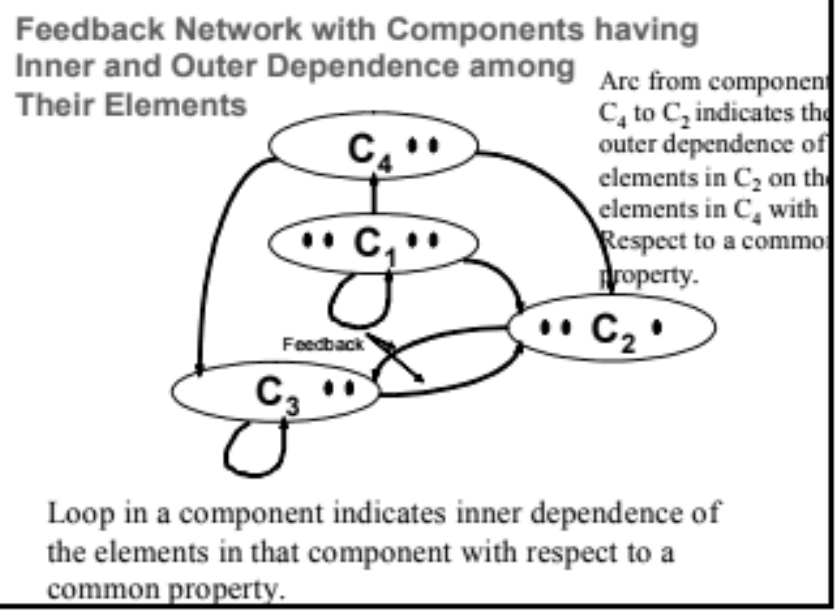


belong to, are the labels of the rows and columns of the supermatrix. The fragment of the supermatrix is shown below (Table 4).

Then, to determine the relative importance of the clusters it is necessary to conduct their pairwise comparisons. The obtained weights are used to weight the supermatrix. It is believed that one cluster affects another cluster (in the diagram, the connection is indicated by an arrow) if at least one element in the source cluster is connected to any node in the target cluster. The clusters connected from the source cluster are pairwise compared for the importance of their impact on it with respect to market share. The result of the comparisons is the column of priorities for that cluster in the cluster matrix. Thus, the result of the procedure of cluster comparisons is a cluster matrix (see Table 5). For example, Merchandise (0.442) and Locations (0.276) have the most impact on the competitors (see the first column of Table 5$)$.

Priorities from the cluster matrix are used to weight blocks of the supermatrix. Thus, the weighted supermatrix is obtained by multiplying each entry in a block of the component at the top of the supermatrix by the priority of influence of the component on the left from the cluster matrix.

Further we can compute the limit supermatrix. The weighted supermatrix is raised to powers until it converges so that all columns are identical (for more details see Saaty, 2001). Limit priorities are normalized and then can be compared with the actual values (reported in the Discount Store News of July 13, 1998, p. 77) shown in Table 6. We see that ANP results are close to the actual relative market share.

Any decision has both positive and negative sides. Thus, to obtain the final decision we should weight and synthesize all favorable and unfavorable concerns. In Saaty (2001) it is suggested that Benefits, Opportunities, Costs and Risks of the

The ANP Structure for the Relative Market Share of Walmart, Kmart and Target

(Saaty, 2008, b)

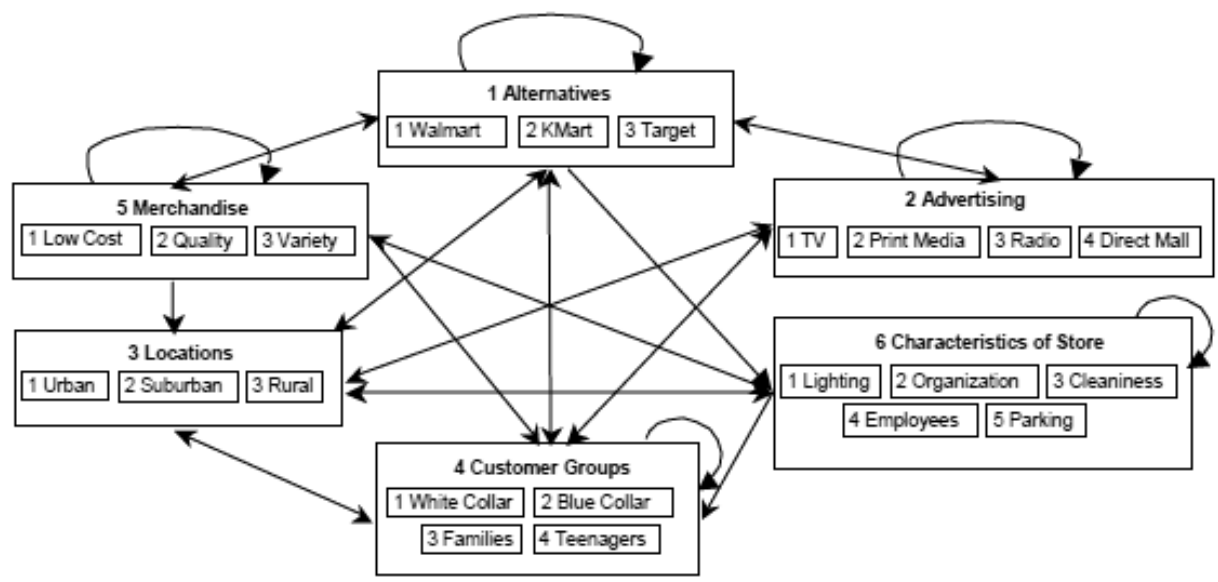


$\frac{\nabla}{\frac{\pi}{2}}$

\begin{tabular}{|c|c|c|c|c|c|c|c|c|c|c|}
\hline & 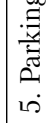 & $\begin{array}{l}\infty \\
1 \\
1 \\
0 \\
0 \\
0\end{array}$ & $\underset{\text { సै }}{\stackrel{0}{0}}$ & $\begin{array}{l}\stackrel{2}{1} \\
\text { ?ִ } \\
0\end{array}$ & $\vdots$ & $\begin{array}{l}\text { م⿱ 口) } \\
\text { ô }\end{array}$ & $\begin{array}{l}0 \\
\stackrel{1}{5} \\
0\end{array}$ & @ & ¿̊. & 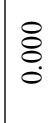 \\
\hline 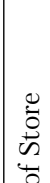 & 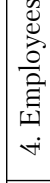 & 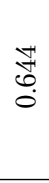 & $\begin{array}{l}10 \\
0 \\
0 \\
0\end{array}$ & 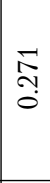 & $\vdots$ & $\begin{array}{l}8 \\
0 \\
0\end{array}$ & 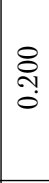 & $\begin{array}{l}8 \\
\infty \\
0 \\
0\end{array}$ & \& & 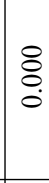 \\
\hline 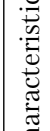 & 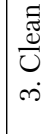 & $\begin{array}{l}\stackrel{P}{0} \\
13 \\
0\end{array}$ & $\begin{array}{l}1 \\
\stackrel{S}{0} \\
0\end{array}$ & חֶֶ & $\vdots$ & $\underset{\vec{N}}{\stackrel{\vec{O}}{0}}$ & $\begin{array}{l}\frac{12}{10} \\
13 \\
0\end{array}$ & : & 芯 & 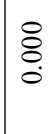 \\
\hline
\end{tabular}

$\frac{n}{\mathbb{3}}$
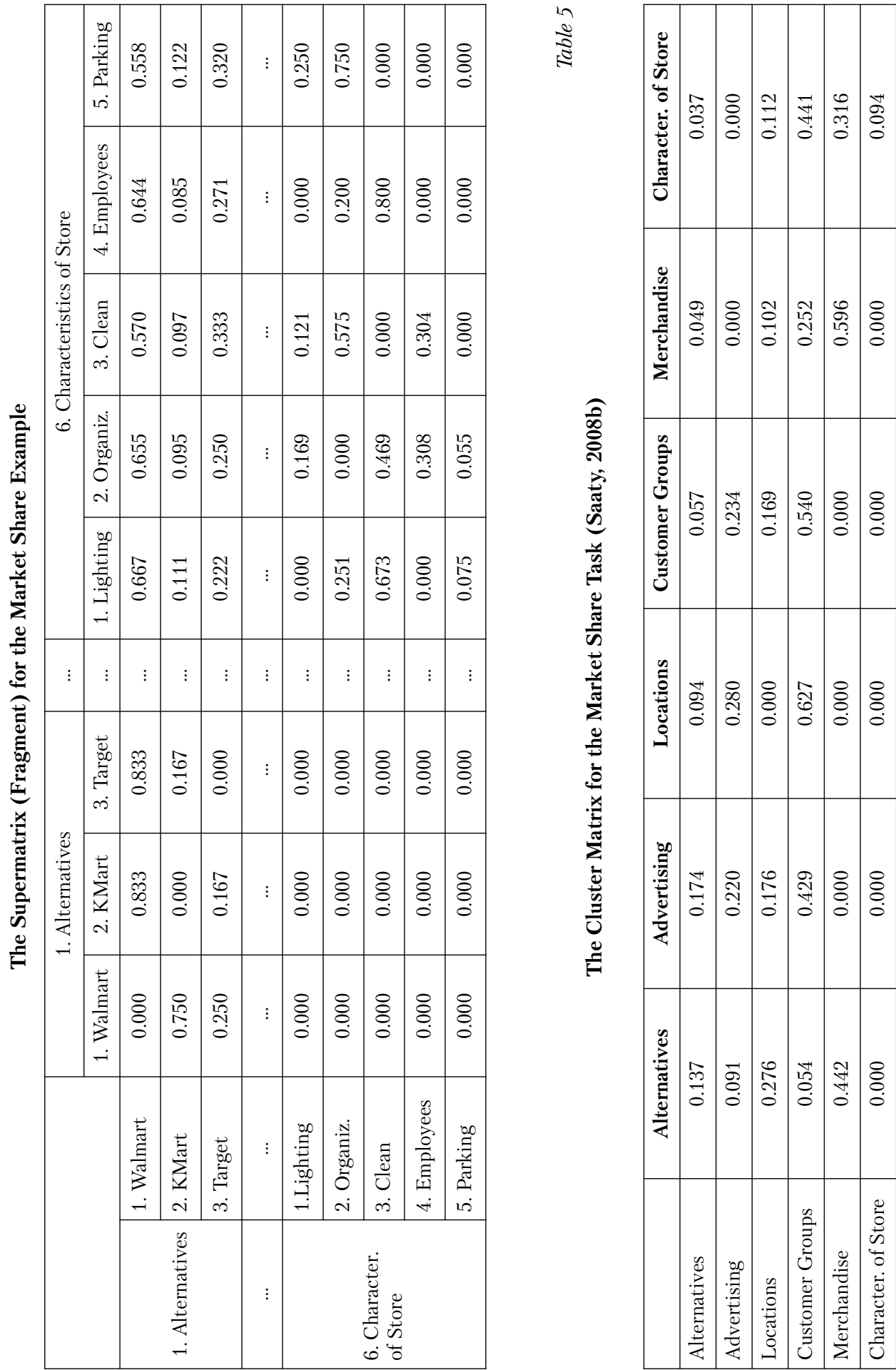

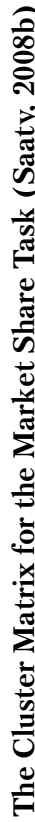

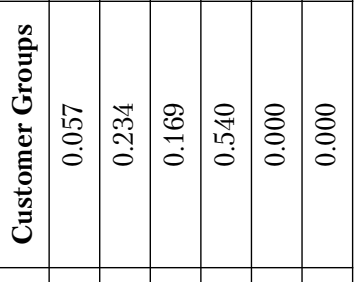

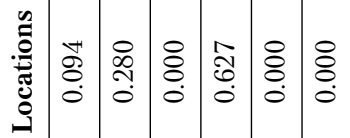

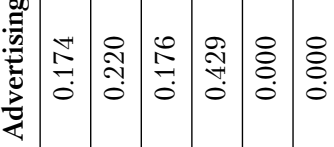

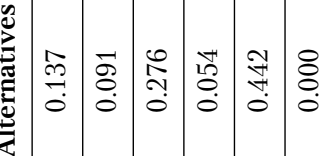

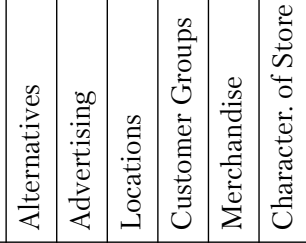


decision should be considered (so-called BOCR model). For each of these four concerns a separate network structure should be constructed.

It is obvious that benefits, opportunities, costs, and risks contribute to the merit of a decision. Each concern must be rated individually on a set of (prioritized) criteria that is used to also rate any other decision. These ratings are called merits and refer to the evaluation criteria to derive them as strategic criteria. Examples of strategic criteria are: satisfaction, happiness, convenience, fulfillment, order, harmony, peace, power, efficiency, social good, progress, wealth and so on (Saaty \& Vargas, 2006). These criteria must be prioritized for frequent use in all decisions. Thus, to obtain their overall synthesis, we must synthesize the outcome of the alternatives for each of the BOCR structures(for the details of synthesizing in BOCR-models see Saaty, 2001; 2009, a).

An example of BOCR-structure is shown in Figure 4. The model was built for the Walt Disney World's problem of searching for areas where it can expand into new markets (see Saaty, 2009, b). Strategic criteria for this model were determined as: Competition, Income Level, Infrastructure, International Character, and Political Support, so B, O, C, and R of the model were evaluated by selecting the appropriate rating category on each strategic criterion (the rating categories were: Very Strong, Strong, Medium, Moderate and Weak). The final results were obtained based on the synthesis of limit priorities of the alternatives in each network and weights of the networks. The alternative with the largest priority is chosen as the best area for expanding.

Broad areas where ANP has been successfully employed include: selection of one alternative from many (for example, Gencer \& Gurpinar, 2007, and Sadeghi, Rashidzadeh, \& Soukhakian, 2012, developed ANP model for supplier selection; Cheng \& Li, 2004 - for contractor selection; Lin, 2010 - for personnel selection); resource allocation (Tripathi \& Vidyarthi, 2015); total quality management (see Forman \& Gass, 2001); public policy (see Saaty \& Vargas, 2006); health care (Liberatore \& Nydick, 2008); strategic planning (Buitrago \& Lesmes, 2010; Saaty, 2009, b; Hosseini, Tavakkoli-Moghaddam, Vahdan, Mousavi, \& Kia, 2013), and others.

Applications of the ANP in decision-making demonstrate that as they experience life people know far more about the world in which they live and more accurately than language alone allows them to express (Saaty \& Vargas, 2006). While

Table 6

The Synthesized Results for the Alternatives in Market Share Example (Saaty, 2008b)

\begin{tabular}{|l|c|c|c|c|}
\hline Alternatives & $\begin{array}{c}\text { Values from } \\
\text { Limit } \\
\text { Supermatrix }\end{array}$ & $\begin{array}{c}\text { Actual Values } \\
\text { July 13, 1998 }\end{array}$ & $\begin{array}{c}\text { Normalized } \\
\text { Values from } \\
\text { Supermatrix }\end{array}$ & $\begin{array}{c}\text { Actual Market } \\
\text { Share as Dollar } \\
\text { Sales Normalized }\end{array}$ \\
\hline Walmart & 0.057 & 58 billion $\$$ & 0.599 & 54.8 \\
\hline KMart & 0.024 & 27.5 billion $\$$ & 0.248 & 25.9 \\
\hline Target & 0.015 & 20.3 billion $\$$ & 0.254 & 19.2 \\
\hline
\end{tabular}


Figure 4

A Decision Sub-Networks with Clusters and Elements for Each of the BOCR

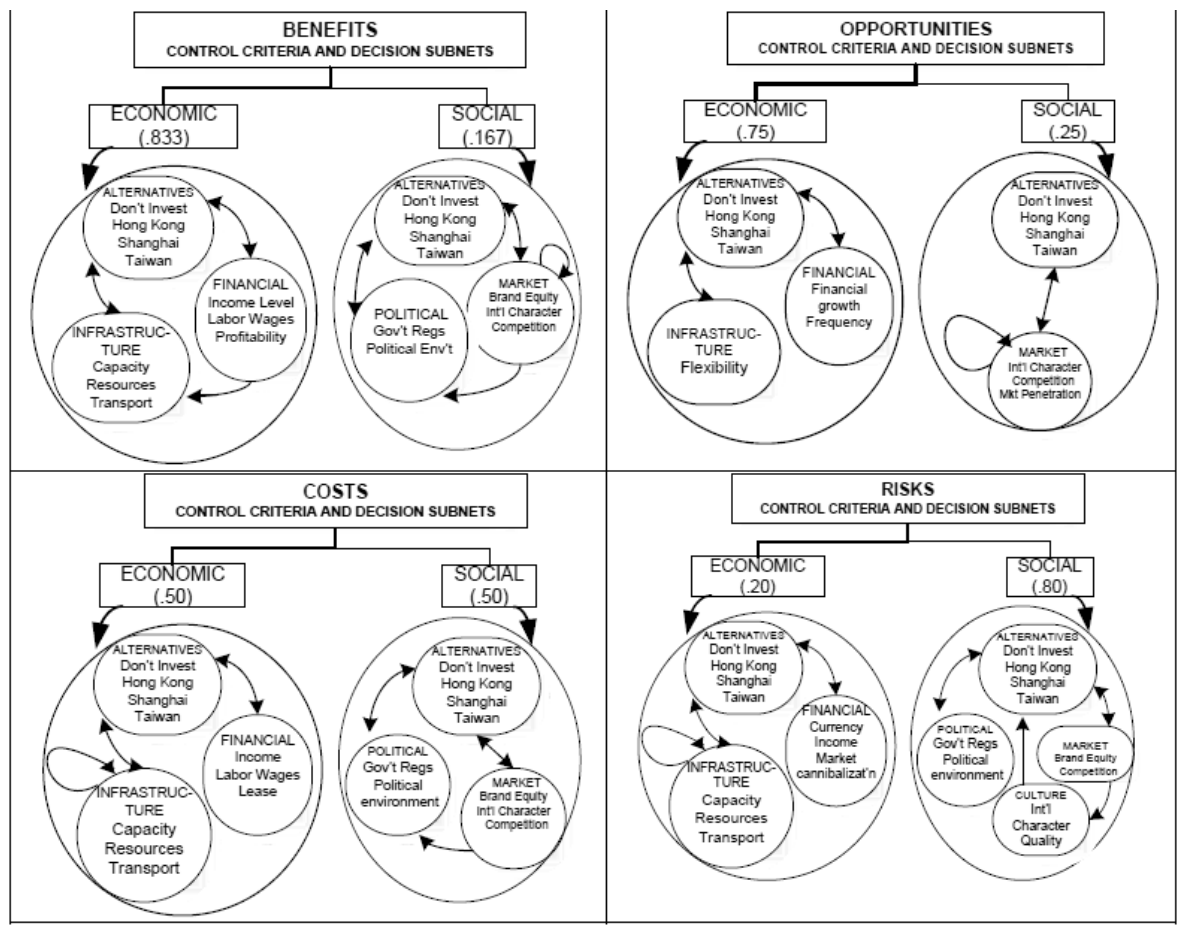

Tversky and Kahneman (1974) observed that people relying on a limited number of heuristics make biased judgments, ANP offers a judgmental structure for evaluation in a consistent manner without simplification of the problem.

We live in a world where there is information overload, and while making decisions we need a way to synthesize priorities in addition to using analysis and applying judgments in each area to create these priorities. It is synthesis that is needed to make good decisions.

Note that synthesis is the main function of our brain, which is primarily a synthesizer of the firings of individual neurons into clusters of information and these in turn into larger clusters and so on, leading to an integrated whole. As our brain consists of parts and subparts that need to mesh together, we have the way to do it using matrix theory that arises from decision-making that has analogous complexity (Saaty, 2015). Thus, ANP provides a mathematical way to synthesize the signals in the brain.

\section{Discussion}

Although heuristics usually govern automatic, intuitive judgments, they can also be used as deliberate mental strategies when working from limited information. In this paper we propose a new look at applying heuristics in advanced decision-making with the Analytic Network Process. 
Undoubtedly the criticism of the ANP, as with any methodology, takes place in different studies. But all criticism relates to the mathematical aspects of the ANP: developing fuzzy concepts of ANP (Zhou, 2012), matrix consistency (Alonso \& Lamata, 2006), synthesizing of alternative priorities for BOCR models (Wijnmalen, 2007), and rank reversal in AHP (Wang \& Luo, 2009).

In comparison with other MCDA approaches that handle uncertainty (MultiAttribute Utility Theory (MAUT), ELECTRE, PROMETHEE, Simple MultiAttribute Rating Technique (SMART), AHP), ANP is the only method that allows the measurement of the dependencies among intangible criteria and alternatives.

But regarding the ANP there are many unexplored psychological questions. We are not able to find studies that compare the results of the ANP with those of fast and frugal heuristics. If the considered problem is intricate, designed networks structure may be too complex and there are no witnesses of the degree of complexity that may be obtained without reducing the quality of perception the comparisons itself. How validity of the results depends on how the comparisons are represented (via matrix or via questionnaire or others)? Many aspects of ANP have yet to be studied, and we hope that this article will draw psychologists' attention to the ANP as a cognitive process.

\section{Conclusion}

Uncertainty is an unavoidable aspect of the human condition. Judgments under uncertainty are often mediated by heuristics, and its study is a fruitful scientific strategy for developing reliable knowledge. In spite of different views on validity of applying heuristics, it is evident that heuristics is a natural instrument of human assessment.

Many studies have been done concerning the role of heuristics in decision-making. The "Heuristics and biases" program introduced by Kahneman and Tversky showed that simple heuristics save effort at the cost of accuracy. Heuristics of the "fast and frugal heuristics" program developed by Gigerenzer and colleagues ignore information to make decisions faster, more frugally, and/or more accurately than more complex methods and strategies (e.g. multiple regression, neural networks, exemplar models, decision-tree algorithms, Pareto/NBD model and others).

However, heuristics may not only be used in fast decisions, but may also be part of deliberate strategies. The ANP offers a judgmental structure for comparisons in a consistent manner without sufficiently reducing the complexity of a problem.

The ANP mathematical approach aims at capturing the grand design and modularity of the brain and its workings. As the brain works through the functioning of its networks of neurons, interactions of the neurons are similar to those of the flow of influences in decision making. Thus, ANP represents the decision problem as a network structure with dependences and feedbacks between included criteria and alternatives. ANP is a descriptive psychophysical process that can be applied to make decisions using heuristics. Whether applying heuristics (based on "System 2") may help to answer questions like "which of the two elements influence more", pairwise comparisons using Fundamental scale give more accurate answers on "how strong is this influence". 
When people make decisions across the boundaries of different areas of information they need a way to synthesize priorities in addition to applying heuristics in each area to make comparisons. ANP provides a mathematical way to synthesize the signals in the brain.

Thus, ANP is a methodology that accurately represents complex problems. Based on heuristics, this strategy helps to find and understand optimal decisions under uncertainty. Studying an impact of applying heuristics in complex models (like ANP) and comparing the results with the fast and frugal approach are, we hope, tasks for future studies.

\section{References}

Alonso, J. A., \& Lamata, M. T. (2006). Consistency in the Analytic Hierarchy Process: a new approach. International Journal of Uncertainty, Fuzziness and Knowledge-Based Systems, 14(4), 445459.

Axelrod, R. M. (1984). The evolution of cooperation. New York: Basic Books.

Boyd, R., \& Richerson, P. J. (2005). The origin and evolution of cultures. New York: Oxford University Press.

Brighton, H. (2006). Robust inference with simple cognitive models. In C. Lebiere, \& B. Wray (Eds.), Between a rock and a hard place: Cognitive science principles meet AI-hard problems: Papers from the AAAI Spring Symposium (pp. 17-22). Menlo Park, CA: AAAI Press.

Buitrago, L., \& Lesmes, D. (2010). Application of the Analytic Network Process (ANP) to select new foreign markets to export software services: study of colombian fims. Escenarios, 8(1), 25-36.

Cheng, E. W. L., \& Li, H. (2004). Contractor selection using the analytic network. Construction Management and Economics, 22, 1021-1032.

Czerlinski, J., Gigerenzer, G., \& Goldstein, D. G. (1999). How good are simple heuristics? In G. Gigerenzer, P. M. Todd, \& the ABC Research Group, Simple heuristics that make us smart (pp. 97-118). New York: Oxford University Press.

Dawes, R. M. (1979). The robust beauty of improper linear models in decision making. American Psychologist, 34, 571-582.

Dehaene, S. (1997). The number sense: How the mind creates mathematics. Oxford: University Press, Inc.

DeMiguel, V., Garlappi, L., \& Uppal, R. (2009). Optimal versus naive diversification: How inefficient is the 1/N portfolio strategy? Review of Financial Studies, 22(5), 1915-1953.

Forman, E. H., \& Gass, S. I. (2001). The Analytic Hierarchy Process: An exposition. Operations Research, 49(4), 469-486.

Frederick, S. (2002). Automated choice heuristics. In T. Gilovich, D. Griffin, \& D. Kahneman (Eds.), Heuristics and biases: The psychology of intuitive judgment (pp. 548-559). New York: Cambridge University Press.

Gencer, C., \& Gurpinar, D. (2007). Analytic Network Process in supplier selection: A case study in an electronic firm. Applied Mathematical Modelling, 31, 2475-2486.

Gigerenzer, G. (2008). Why heuristics work. Perspectives of Psychological Science, 3(1), 20-29.

Gigerenzer, G., \& Gaissmaier, W. (2011). Heuristic decision making. Annual Review of Psychology, 62, 451-482.

Gigerenzer, G., \& Goldstein, D. G. (1996). Reasoning the fast and frugal way: Models of bounded rationality. Psychological Review, 103(4), 650-669.

Gigerenzer, G., Hertwig, R., \& Pachur, T. (2011). Heuristics: The foundations of adaptive behavior. New York: Oxford University Press.

Gilovich, T., Griffin, D., \& Kahneman, D. (Eds.). (2002). Heuristics and biases: The psychology of intuitive judgment. New York: Cambridge University Press. 
Goldstein, D. G., \& Gigerenzer, G. (2002). Models of ecological rationality: The recognition heuristic. Psychological Review, 109(1), 75-90.

Hogarth, R. M., \& Karelaia, N. (2005). Ignoring information in binary choice with continuous variables: When is less "more"? Journal of Mathematical Psychology, 49, 115-124.

Hogarth, R. M., \& Karelaia, N. (2006). "Take-the-best" and other simple strategies: Why and when the work "well" with binary cues. Theory and Decision, 61, 205-249.

Hogarth R. M, \& Karelaia N. (2007). Heuristic and linear models of judgment: matching rules and environments. Psychological Review, 114(3), 733-758.

Hosseini, L., Tavakkoli-Moghaddam, R., Vahdan, B., Mousavi, S. M., \& Kia, R. (2013). Using the Analytical Network Process to select the best strategy for reducing risks in a supply chain.Journal of Engineering, 2013, 375628.

Johnson, E. J., \& Goldstein, D. G. (2003). Do defaults save lives? Science, 302, 1338-1339.

Johnson, J. G., \& Raab, M. (2003). Take the first: option generation and resulting choices. Organizational Behavior and Human Decision Processes, 91, 215-29.

Kahneman, D. (2003). A perspective on judgment and choice: Mapping bounded rationality. American Psychologist, 58(9), 697-720.

Kahneman, D., \& Frederick, S. (2002). Representativeness revisited: Attribute substitution in intuitive judgment. In T. Gilovich, D. Griffin, \& D. Kahneman (Eds.), Heuristics and biases (pp. 49-81). New York: Cambridge University Press.

Kahneman, D., \& Tversky, A. (1996). On the reality of cognitive illusions. Psychological Review, 103(3), 582-591.

Katsikopoulos, K. V., \& Martignon, L. (2006). Nanve heuristics for paired comparisons: Some results on their relative accuracy. Journal of Mathematical Psychology, 50(5), 488-494.

Katsikopoulos, K. V., Schooler, L. J., \& Hertwig, R. (2010). The robust beauty of ordinary information. Psychological Review, 117(4), 1259-1266.

Kelley, C. M., \& Jakoby, L. L. (1996). Adult egocentrism: Subjective experience versus analytic bases for judgment. Journal of Memory and Language, 35, 157-175.

Liberatore, M. J., \& Nydick, R. L. (2008). The Analytic Hierarchy Process in medical and health care decision making: A literature review. European Journal of Operational Research, 189(1), 194-207.

Lin, H.-T. (2010). Personnel selection using Analytic Network Process and fuzzy data envelopment analysis approaches. Computers and Industrial Engineering, 59(4), 937-944.

Martignon, L., \& Hoffrage, U. (2002). Fast, frugal, and fit: simple heuristics for paired comparisons. Theory and Decision, 52(1), 29-71.

McCammon, I., \& Hageli, P. (2007). An evaluation of rule-based decision tools for travel in avalanche terrain. Cold Regions Science and Technology, 47(1-2), 193-206.

Miller, G. A. (1956). The magical number seven plus or minus Two: Some limits on our capacity for processing information. Psychological Review, 63, 81-97.

Mousavi, S., \& Gigerenzer, G. (2014). Risk, uncertainty, and heuristics. Journal of Business Research, 67, 1671-1678.

Pachur, T., \& Biele, G. (2007). Forecasting from ignorance: The use and usefulness of recognition in lay predictions of sports events. Acta Psychologica, 125(1), 99-116.

Petrie, M., \& Halliday, T. (1994). Experimental and natural changes in the peacock's (Pavo cristatus) train can affect mating success. Behavioral Ecology and Sociobiology, 35(3), 213-217.

Pohl, R. F. (2006). Empirical tests of the recognition heuristic. Journal of Behavioral Decision Making, 19(3), 251-271.

Reber, R., Winkielman, P., \& Schwarz, N. (1998). Effects of perceptual fluency on affective judgments. Psychological Science, 9, 45-48. 
Saaty, T. L. (1990). How to make a decision: the Analytic Hierarchy Process. European Journal of Operational Research, 48, 9-26.

Saaty, T. L. (2001). Decision making with dependence and feedback: The Analytic Network Process. Pittsburgh, PA: RWS Publications.

Saaty, T. L. (2008, a). Relative measurement and its generalization in decision making: Why pairwise comparisons are central in mathematics for the measurement of intangible factors. RACSAM, 102(2), 251-318.

Saaty, T. L. (2008, b). The Analytic Hierarchy and Analytic Network Measurement Processes: Applications to decisions under risk. European Journal of Pure and Applied Mathematics, 1(1), 122-196.

Saaty, T. L. (2009, a). Theory and applications of the Analytic Network Process: Decision making with benefits, opportunities, costs and risks. Pittsburgh, PA: RWS Publications.

Saaty, T. L. (2009, b). Applications of Analytic Network Process in entertainment. Iranian Journal of Operations Research, 1(2), 41-55.

Saaty, T. L. (2013). On the measurement of intangibles. A principal eigenvector approach to relative measurement derived from paired comparisons. Notices of the American Mathematical Society, 60(2), 192-208.

Saaty, T. L. (2015). The Neural Network Process (NNP). The fundamental equation of neural response and consciousness. Pittsburgh, PA: RWS Publications.

Saaty, T. L., \& Vargas, L. G. (2006). Decision making with the Analytic Network Process: Economic, political, social and technological applications with benefits, opportunities, costs and risks. New York: Springer.

Sadeghi, M., Rashidzadeh, M., \& Soukhakian, M. (2012). Using Analytic Network Process in a group decision-making for supplier selection. Informatica (Netherlands), 23(4), 621-643.

Schooler, L. J., \& Hertwig, R. (2005). How forgetting aids heuristic inference. Psychological Revieze, 112(3), 610-628.

Schulkin, J. (Ed.). (2012). Action, perception and the brain: Adaptation and cephalic expression. New York: Palgrave Macmillan.

Simon, H. A. (1956). Rational choice and the structure of the environment. Psychological Review, 63(2), 129-138.

Simon, H. A. (1957). Models of man. New York: Wiley \& Sons.

Stanovich, K. E. (2009). What intelligence tests miss: the psychology of rational thought. New Haven, CT: Yale University Press.

Todd, P. M., Gigerenzer, G., \& the ABC Research Group. (2012). Ecological rationality: Intelligence in the world. New York: Oxford University Press.

Tripathi A., \& Vidyarthi D. P. (2015). Task allocation on cloud resources using Analytic Network Process. 2015 International Conference on Advances in Computer Engineering and Applications, Art. 7164847, 971-978. doi:10.1109/ICACEA.2015.7164847

Tversky, A., \& Kahneman, D. (1974). Judgment under uncertainty: Heuristics and biases. Science, 185(4157), 1124-1131.

Tversky, A., \& Kahneman, D. (1983). Extensional versus intuitive reasoning: The conjunction fallacy in probability judgment. Psychological Review, 90, 293-315.

Wang, Y., \& Luo, Y. (2009). On rank reversal in decision analysis. Mathematical and Computer Modelling, 49(5-6), 1221-1229.

Wang, Y., \& Wang, Y. (2006). Cognitive informatics models of the brain. IEEE Transactions on Systems, Man, and Cybernetics, Part C, 36(2), 203-207.

Wijnmalen, D. J. D. (2007). Analysis of benefits, opportunities, costs, and risks (BOCR) with the AHPANP: A critical validation. Mathematical and Computer Modelling, 46, 892-905.

Wübben, M., \& Wangenheim, F. (2008). Instant customer base analysis: Managerial heuristics often "Get It Right”. Journal of Marketing, 72, 82-93. 
Zhou, X. (2012). Fuzzy Analytical Network Process implementation with Matlab. In V. N. Katsikis (Ed.), MATLAB - A fundamental tool for scientific computing and engineering applications (Vol. 3). doi:10.5772/46466. Retrieved from https://www.intechopen.com/books/matlab-a-fundamental-tool-

Maria A. Milkova - research fellow, Central Economics and Mathematics Institute, Russian Academy of Sciences.

Research area: behavioral economics, decision-making under uncertainty, machine learning. E-mail: m.a.milkova@gmail.com

Alexander V. Andreichicov - professor, Russian University of Transport, D.Sc., professor. Research area: conceptual design, artificial intelligence, methods of artificial intelligence, mathematical simulation, mathematical methods of multi-criteria decision analysis, decision-making, artificial intelligence, psychology of engineering creativity.

E-mail: andreichickov@mail.ru

Olga N. Andreichicova - leading research fellow, Central Economics and Mathematics Institute, Russian Academy of Sciences, D.Sc., professor.

Research area: systems analysis, mathematical simulation, mathematical methods of multi-criteria decision analysis, decision-making, artificial intelligence, psychology of engineering creativity.

E-mail: alexandrol@mail.ru

\title{
Принятие решений в условиях неопределенности: подходы на основе эвристик и метод аналитических сетей
}

\author{
М.А. Милкова ${ }^{\mathrm{a}}$, А.В. Андрейчиков ${ }^{\mathrm{b}}$, О.Н. Андрейчикова ${ }^{\mathrm{a}}$ \\ ${ }^{a}$ Центральный экономико-математический институт РАН, 117418, Россия, Москва, \\ Нахимовский просп., $\partial .47$ \\ ${ }^{b}$ Российский университет транспорта, 127055, Россия, Москва, ул.Образиова, д. 9 , стр. 9
}

\section{Резюме}

Данная статья представляет собой обзор известных эвристических алгоритмов и различных взглядов на принятие решений на основе эвристик. В статье обсуждаются эвристики и необъективность (смещения), рассмотренные Даниэлем Канеманом и Амосом Тверски, а также быстрые и экономичные эвристики, предложенные Гердом Гигеренцером и коллегами. Мы предлагаем идею о том, что эвристики, будучи естественным инструментом человеческого оценивания, могут использоваться не только для упрощения процесса принятия решений, но также и в продуманных стратегиях, без существенного упрощения рассматриваемой проблемы. В свете данного предположения в статье дается обзор метода аналитических сетей (Analytic Network Process, ANP) как когнитивного процесса. Метод аналитических сетей - описательный психофизический процесс, разработанный математиком, заслуженным профессором Питтсбургского университета Томасом Саати в 1980-х гг. и используемый для крупномасштабного многокритериального подхода к принятию решений. ANP представляет рассматриваемую проблему в качестве сетевой структуры с зависимостями и обратными связями между критериями и альтернативами. В то время как использование эвристик может дать ответ на вопрос 
«какой из двух рассматриваемых элементов больше влияет на третий элемент», применение системы попарных сравнений элементов (один из основных этапов ANP) дает ответ на вопрос «насколько сильно данное влияние». Данная статья преследует цель обратить внимание психологического сообщества на возможность междисциплинарного исследования метода аналитических сетей, который ранее рассматривался только в качестве математического алгоритма, а не когнитивного процесса.

Ключевые слова: принятие решений в условиях неопределенности, когнитивные искажения, быстрые и экономичные эвристики, метод аналитических сетей.

Милкова Мария Александровна - научный сотрудник, Центральный экономико-математический институт РАН.

Сфера научных интересов: принятие решений в условиях неопределенности, машинное обучение, поведенческая экономика.

Контакты: m.a.milkova@gmail.com

Андрейчиков Александр Валентинович - профессор, Российский университет транспорта, доктор технических наук, профессор.

Сфера научных интересов: принятие решений, искусственный интеллект, психология инженерного творчества, концептуальное проектирование, математическое моделирование и математические методы анализа многокритериальных решений.

Контакты: andreichickov@mail.ru

Андрейчикова Ольга Николаевна - ведущий научный сотрудник, Центральный экономико-математический институт РАН, доктор технических наук, профессор.

Сфера научных интересов: принятие решений, искусственный интеллект, психология инженерного творчества, системный анализ, математическое моделирование и математические методы анализа многокритериальных решений.

Контакты: alexandrol@mail.ru 